$5 \mathrm{~s}$

To the Editors:

\title{
Hookworm infection as a cause of melaena
}

The case report by Lamabadusuriya and Perera (1) highlights an unusual manifestation of hookworm infection. However, melaena due to hookworm infection is not as rare as the authors seem to imply, especially in the paediatric age group. A review of infantile hookworm disease in China found that it has been reported in over 500 infants since the 1960 s and melaena was the most frequent manifestion (in 75 to $100 \%$ of cases) which brought the baby to hospital (2).

There are some unusual features in their case report (1). Firstly, the age of the child: at 2 years, this child is older than those reported in China, nearly all of whom were below 12 months of age, including many who developed disease in the first month of life, perhaps from transmammary transmission. Secondly, the species of parasite: all except one of the Chinese cases were caused by Ancylostoma duodenale. This species is said to cause more blood loss and damage to the small intestinal mucosa than Necator americanus, the offending parasite in the local case report. Finally, the results of stool examination for helminth ova are most surprising: the initial report was negative for hookworm ova, and subsequent examination gave a count of 150 hookworm eggs / gram faeces. This count qualifies for classification only as a light infection, according to WHO criteria (< 2000 epg faeces) (3), and is not in accordance with the endoscopic findings of "a large number of worms attached to the seound part of the doodenal mucosa" (1). Melaena woold nor the occurred unless there was a sizeable population of abian nockworms present in the child's small inescine, is is uritiseily that the low count was due to immaturity of the warn population, for the case history states than the chilid was an the Lady Ridgeway Hospital for over a month. ping artplic time for maturation of female worms as the saype af esd production. The most probable explansoicn is thur the first haberatory reports were incorrect.

This case repor serves as a amely reminder that foci of intestinal nemanoule affectoins seil remain in parts of Sri Lanka where socio-ecrinarmic curnditions are poor and latrines abseat. in also enphusaiss the fact that personnel in Sri Lankan hospiail labinaries stiould be better trained to carry out the sirngic, inezpersive laboratory tests for stool examination fix ancsinal jeranode ova.

\section{References}

1. Lamabaduscriga S. Furus S kx ansul cuse of melaena in a

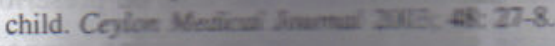

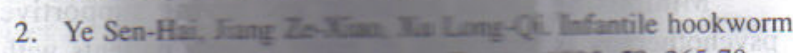
disease in Crima. A mexies Aste Tropices 1995; 59: 265-70.

3. Prevention and cunnal ur sensassiriusis and soil-transmitted

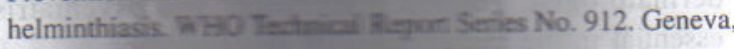

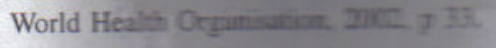

Nilanthi de Silva, Department of Parasitology, Faculty of Medicine, Universen of Zaime (Correspondence: E-mail:nrdes@sitnet.lk. Competing interests: None declared. Received 12 May 2023 amestis May 2003). 